\title{
Los ecos de Lepanto en la catedral de Toledo
}

\author{
Echoes of Lepanto in the Toledo Cathedral
}

\author{
Dr. J. Carlos VIZUETE MENDOZA* \\ Universidad de Castilla-La Mancha
}

\begin{abstract}
Resumen: En 1574, para conmemorar la victoria en la batalla de Lepanto, Felipe II instituyó y dotó en la catedral de Toledo, como primada de España, una memoria anual que debía celebrarse cada 7 de octubre en acción de gracias por el triunfo de la armada cristiana sobre el turco. Para que se exhibieran en aquella ocasión se comprometió a enviar unas banderas e insignias de la victoria de las que hoy se conservan las que ondearon en la galera de don Juan de Austria.
\end{abstract}

Abstract: In 1574, in order to commemorate the victory in the battel of Lepanto, Philip II instituted and endowed in Toledo Cathedral, as the see of the Primate of Spain, an annual memory to be held every October the 7th as thanksgiving for the victory of the Christian navy over the Turk. In order to be exhibited on that occasion, he pledged of sending some flags and victory insignia, of which today, those that waved in Don Juan of Austria's galley, are preserved.

Palabras Clave: Batalla de Lepanto, Catedral de Toledo, Fiesta litúrgica, Felipe II.

Keywords: Battle of Lepanto, Toledo Cathedral, Liturgical festivity, Philip II.

\section{Sumario:}

I. Una victoria milagrosa.

1.1. La revelación de la victoria a Pío $V$.

1.2. De los santos a la Virgen.

\footnotetext{
* Profesor Titular de Historia Moderna, Facultad de Humanidades de Toledo. Carlos.Vizuete@uclm.es; ORCID: 0000-0003-4619-7876.
} 
II. La fiesta en la catedral de Toledo.

2.1. La dotación.

2.2. La fiesta litúrgica.

III. Las banderas de Lepanto.

IV. Bibliografía.

Recibido: octubre 2021.

Aceptado: noviembre 2021. 


\section{UNA VICTORIA MILAGROSA}

Desde el primer momento, tanto los protagonistas como los coetáneos de la "Victoria Naval"1 no tuvieron ninguna duda de que aquélla se había producido por intervención divina y la calificaron de milagrosa ${ }^{2}$. Las representaciones que cantan el triunfo -en pintura, grabados o medallas- así lo recogen, y en ellas vemos cómo Cristo, la Virgen, los ángeles y los santos colaboran desde el cielo en la victoria de las armas cristianas $^{3}$, pues al cabo la Liga Santa había sido concebida como una cruzada por su impulsor, el papa Pío $\mathrm{V}^{4}$.

\subsection{La revelación de la victoria a Pío $V$}

En 1595 apareció en Madrid una biografía de este Papa $^{5}$ escrita por Antonio de Fuenmayor ${ }^{6}$ cuya fuente, a decir de Nicolás Antonio, era Francisco de Reinoso, un clérigo palentino que tras graduarse en Artes y Teología en Salamanca y ordenarse de Epístola en Ávila marchó a Roma donde entró al servicio del cardenal dominico Antonio Miguel Ghislieri, que en 1566 se convertiría en el papa Pío V. Durante todo su pontificado, Reinoso seguiría a su servicio como

\footnotetext{
${ }^{1}$ Durante mucho tiempo esta fue la denominación preponderante, en los documentos y en las obras literarias, para referirse a la batalla de Lepanto.

${ }^{2}$ El grabador veneciano Giacomo Franco (1560-1620) tituló una de sus estampas, con la disposición de las dos armadas frente a frente y la última fase de la batalla, Miraculosa victoria a Deo Christianis contra Turca tributa (Venecia, 1596).

${ }^{3}$ El tema ha sido tratado por MÍNGUEZ CORNELLES, V., "Iconografia de Lepanto. Arte, propaganda y representación simbólica de una Monarquía universal y católica", en Obradoiro de Historia Moderna (Santiago de Compostela), 20 (2011) 255-284; y más ampliamente en la monografía Infierno y gloria en el mar. Los Habsburgo y la imagen artística de Lepanto (14301700), Castellón de la Plana 2018.

${ }^{4}$ RIVERO RODRÍGUEZ, M., La batalla de Lepanto. Cruzada, guerra santa e identidad confesional, Madrid 2008, pp. 136-137.

${ }^{5}$ Vida y hechos de Pio V, Pontifice Romano, con algunos notables sucesos de la Christiandad del tiempo de su Pontificado. En Madrid, por Luis Suárez, 1595.

${ }^{6}$ Pese a que en algunos catálogos se le identifica como jesuita, Nicolás Antonio dice que fue canónigo y arcediano de Campos en la catedral de Palencia: ANTONIO, N., Bibliotheca Hispana Nova, Romae, ex Officina Nicolai Angeli Tinasii, 1672, vol. I, p. 94.
} 
mayordomo y camarero secreto ${ }^{7}$. A la muerte del Papa regresó a Palencia donde obtuvo una dignidad en el cabildo catedralicio (1573) y el beneficio de la Abadía de Husillos $(1577)^{8}$, después de no haber podido tomar posesión del arcedianato de Toledo que le concediera Pío V en $1571^{9}$. En aquellos años palentinos debió compartir con el arcediano de Campos las confidencias que éste incorporaría a su Vida de Pío $V$.

El libro sexto de esta obra está dedicado a los acontecimientos de los últimos años del pontificado (1570-1572) y comienza con la invasión de la isla de Chipre por los turcos. Después de narrar la iniciativa del Papa en la formación de la Liga con el rey Católico y la República de Venecia, conseguida tras salvar grandes dificultades, se detiene en «la gran victoria de Lepanto, de las armadas coaligadas contra la turquesca, con grandes señales de milagros" ${ }^{\prime 10}$ ¿ ¿Cuáles fueron éstas? Antonio de Fuenmayor, tras describir brevemente la batalla, las enumera:

"Túvose la victoria, de los que bien la consideran, por milagrosa en que mostró Dios la concedía a las oraciones de su siervo Pío. Los esclavos turcos confesaron haber visto ángeles con espadas desnudas sobre nuestras galeras. Por eso en la sala Real del Vaticano se pintó san Pedro y san Pablo y un ejército de ángeles que por la armada de la Liga peleaba contra el poder del infierno, y se batieron medallas con la misma figura. También, según los más cursados en aquellos mares, fue contra la naturaleza de ellos la mudanza del aire que siendo, al descubrirse las armadas, favorable al enemigo se volvió contrario, aunque allí después de mediodía suelen esforzarse los Lestes, vientos de tierra. Con esto cegaba el humo a los enemigos y el sol, que al nacer daba en el rostro a los nuestros, estando a más de la mitad del cielo cuando comenzó a pelearse, hería en los ojos al contrario. Fue gran suerte el descubrir tan a tiempo la armada turquesca

${ }^{7}$ ALFARO, Fray G. de, Vida del Illustríssimo Señor Don Francisco de Reynosso, obispo de Córdoba, Valladolid, por Francisco Fernández de Córdoba, 1617; ENTRAMBASAGUAS, J. de, Vida ejemplar de Francisco de Reinoso, Abad de Husillos y Obispo de Córdoba, Valladolid 1940.

${ }^{8}$ SAN MARTÍN PAYO, J., "Notas históricas sobre la Abadía de Husillos", en Publicaciones de la Institución Tello Téllez de Meneses (Palencia), 64 (1993) 226-229 // 197-236.

${ }^{9}$ El 26 de febrero de 1571 murió el arcediano Fernando de Mendoza, hermano del cardenal de Burgos; como era uno de los meses en los que la provisión tocaba al Pontífice éste hizo la colación en su mayordomo. Felipe II no la aceptó pues prefería que la dignidad quedara en alguno de los Mendoza, y el Consejo ordenó no darle la posesión por inhábil ya que incumplía claramente el estatuto de limpieza de sangre: su madre, Juana de Baeza, tenía ascendientes de origen converso y sus hermanas Catalina y Francisca, monjas cistercienses en el convento de Belén, fueron condenadas por luteranismo en el auto de fe de Valladolid de 8 de octubre de 1559. Reinoso renunció al arcedianato resignándolo en su pariente Francisco de Ávila, que tomó posesión el 1 de julio de 1572, y se reservó una pensión sobre la dignidad. Archivo Capitular de Toledo (ACT), Secretaría Capitular, v. 1, Libro de Sucesión de Prebendas, f. 30.

${ }^{10}$ FUENMAYOR, A., Vida y hechos de Pio V, f. 122. 
para poder concertarse, porque en el orden estuvo la victoria. Pareció del Cielo la seguridad de ánimos en los nuestros, el poco cuidado que de huir tuvieron, tanto que don Juan, para hacer mayor plaza en que pelear, desbancó su galera como si morir o vencer fuera el fin de aquel día. No quiso Dios tener suspenso a su santo mucho tiempo, esperando a que perezosos correos le trajesen la nueva, y con embajada suya le avisó al instante. El día de la victoria, que fue a 7 de octubre de 71, se paseaba con el tesorero ${ }^{11} \mathrm{y}$, súbitamente, se apartó de él, abrió una ventana y estuvo mirando al cielo como atónito. Cerróla de allí a poco y dijo al tesorero: Andad con Dios, no es tiempo de negocios sino de dar gracias a Cristo, porque nuestra armada venció a este punto. Íbase y volviendo la cabeza vio al Pontífice postrado delante de un crucifijo que tenía siempre donde estaba y por eso le pintan con él en las manos. Por parecerle caso grave, en que se disminuiría la autoridad de Pío a no ser cierto, lo disimuló como hombre cuerdo notando sólo por escrito el día y la hora, que averiguó ser el mismo en que los nuestros apellidaron victoria. Pero el cardenal Cesi ${ }^{12}$, que no lejos estaba, lo entendió todo y descubrió a algunos familiares del Pontífice mucho antes. Dadas las gracias, se salió al campo a pasear, con rostro tan alegre que lo advirtieron cuantos le seguían. Un mensajero que envió el general con el aviso se detuvo por el tiempo contrario y Pío se admiró muchas veces delante de los suyos de cómo tardaban las nuevas de la victoria. Dijo siempre en público que los nuestros pelearían y vencerían desde que supo la resolución con la que salieron de Mesina. Y lo que más muestra cuán por puntos tenía revelación del suceso de la armada, el mismo día de la batalla y la noche antes hizo doblar las oraciones en todos los conventos y que a todas horas asistiesen a aplacar a Dios devotos religiosos. Él, con tantos ayunos, suspiros y lágrimas, pidió el buen suceso que mereció ser oído. Llegó ya el correo y el pueblo dio gracias a Dios de la victoria en la iglesia de San Pedro" ${ }^{13}$.

Así, en una de las primeras obras pictóricas que representa la batalla de Lepanto, la encargada por el mismo papa Pío V a Giorgio Vasari en 1572 para decorar al fresco uno de los muros de la Sala Regia del Vaticano, puede verse en el ángulo superior izquierdo cómo Cristo, cual Júpiter tonante, fulmina con un rayo a la armada turca acompañado de los santos patronos de los países integrantes de la Liga Santa armados con espadas: san Pedro y san Pablo (la Santa Sede),

${ }^{11}$ Bartolomeo Bussotti (ca. 1520-1576) nombrado por Pío V, poco después de su elección, tesorero general de la Iglesia en sustitución de Donato Mateo Minali, sobre el que pesaban sospechas de irregularidad en su administración.

${ }^{12}$ Pierdonato Cesi (1522-1586), cardenal de Santa Bárbara.

${ }^{13}$ FUENMAYOR, A., Vida y hechos de Pio V, ff. 137-138. He modernizado la ortografía y la puntuación del texto. 
Santiago (España) y san Marcos (Venecia); junto con un ejército de ángeles que lanzan dardos sobre las galeras otomanas. El enorme fresco vaticano fue rápidamente difundido por medio de estampas, como la grabada por Giovanni Battista de Cavalieri en 1572 (figura 1).

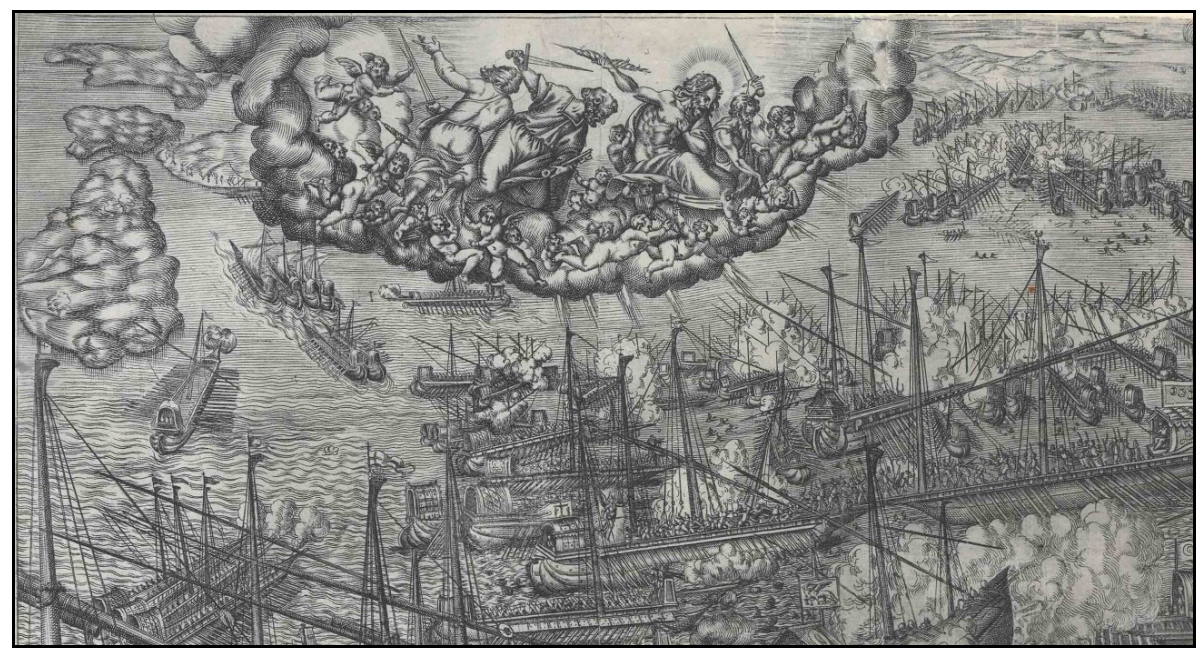

Figura 1: Giovanni Battista de Cavalieri, La batalla de Lepanto (fragmento), Roma 1572. (BNE, Estampas, INVENTARIO/14727).

Mandó, también, Pío V acuñar en plata una medalla conmemorativa de la victoria; en el anverso aparece el retrato de busto del Pontífice, con camauro y muceta, rodeado por la inscripción: PIVS $\cdot \mathrm{V} \cdot \mathrm{PONT} \cdot \mathrm{OPT} \cdot \mathrm{MAX} \cdot \mathrm{ANNO} \mathrm{VI} \cdot$ y en el reverso se representa a Cristo que desde el cielo lanza rayos con su mano derecha sobre las naves de la flota otomana, con la inscripción: DEXTERA . TVA $\cdot$ DOM $\cdot$ PERCVSSIT $\cdot$ INIMICVM $\cdot 1571^{14}$.

Si en la medalla, por las pequeñas dimensiones del campo, han desaparecido los santos Pedro y Pablo, en el relieve que representa la batalla en el monumento funerario de Pío V, en la capilla Sixtina de la basílica de Santa María la Mayor de Roma $^{15}$, quien desaparece es el Salvador y son los santos Apóstoles los que expulsan del cielo al dragón infernal mientras en el mar las galeras cristianas baten a las otomanas.

\footnotetext{
${ }^{14}$ La medalla fue grabada por Gian Federico Bonzagna en 1571. Un ejemplar en el Museo del Prado, número de catálogo 0001011.

${ }^{15}$ Encargada por Sixto V a Domenico Fontana para albergar tanto su tumba como la de Pío V, que le había creado cardenal. Las trazas del monumento funerario de Pío V, un enorme retablo marmóreo, datan de 1585.
} 
Un último ejemplo de la atribución de la victoria a la intercesión de los santos patronos de los miembros de la Liga Santa es la estampa alegórica de su triunfo, grabada por Andreas Marelli en 1572 en Roma (figura 2). En ella parecen arrodillados, delante de la representación de las flotas dispuestas para el combate, los soberanos de las naciones coaligadas: Pío V, acompañado de dos cardenales, Felipe II y el Dux de Venecia, Alvise Mocenigo; de pie, delante de ellos, los santos protectores: san Jorge (corona de Aragón), Santiago (corona de Castilla), san Marcos (Venecia) y san Juan Bautista (Génova). Sobre ellos, en un rompimiento de cielos, Cristo resucitado flanqueado por los santos Pedro y Pablo. Cuatro ángeles tenantes sostienen los escudos heráldicos de don Juan de Austria, Felipe II, la Serenísima República de Venecia y Marco Antonio Colonna.

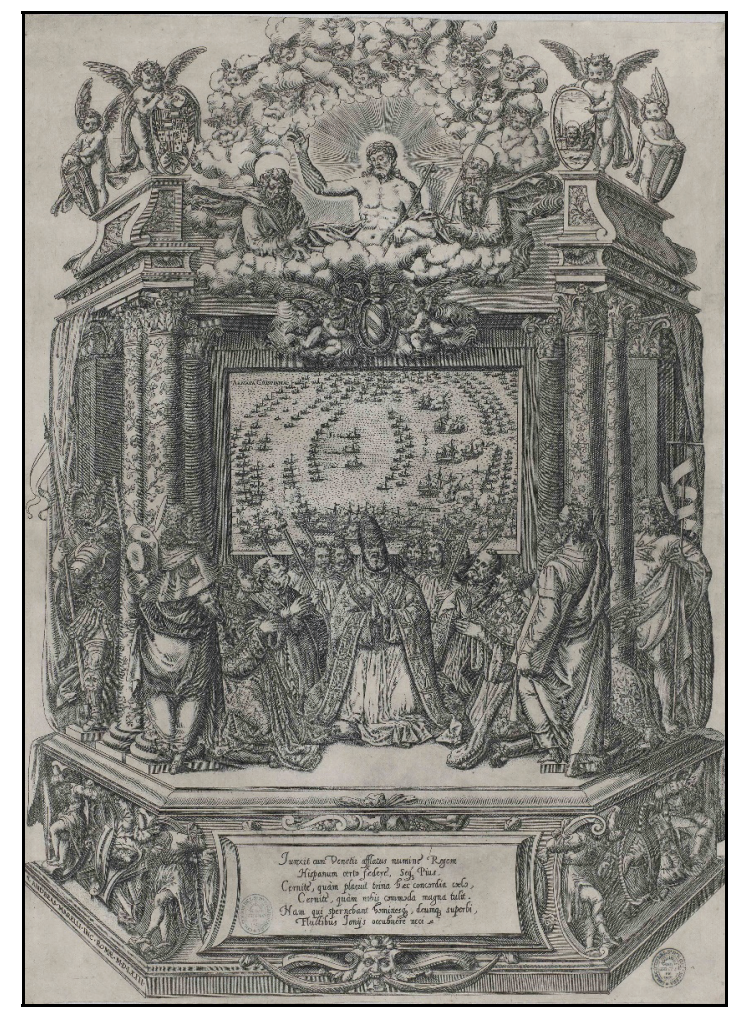

Figura 2: Andreas Marelli, Alegoría del triunfo de la Liga Santa, Roma 1572. (BNE, Estampas, INVENTARIO/14726).

Sin embargo, tras la muerte de Pío V las representaciones de la victoria de la batalla de Lepanto comienzan a asociarse a la Virgen María, en la advocación del Rosario, especialmente en las obras pintadas con motivo de su beatificación (1672) y de su canonización (1712). 


\subsection{De los santos a la Virgen}

Siendo todavía cardenal, Pío V adquirió unos terrenos en las afueras de su localidad natal, Bosco Marengo, para fundar allí un convento de la orden dominicana, lo que hizo en 1566, siendo ya Papa, edificando el convento de Santa Croce e Tutti i Santi. Sobre el altar de la capilla del Rosario de la iglesia conventual se encuentra un gran lienzo de Grazio Cossali, fechado en 1597, que representa a la Virgen del Rosario entre santo Domingo de Guzmán y santa Catalina de Siena, en la parte inferior, en actitud orante, a la derecha el cardenal Bonelli ${ }^{16}$ y Pío V, a la izquierda Felipe II y el dux Alvise Mocenigo, y entre ambos grupos un angelote sostiene el estandarte de la Liga Santa, en alusión a la victoria obtenida por la intercesión de la Virgen del Rosario.

Pinturas posteriores fijarán la iconografía de la visión de Pío V de la victoria de Lepanto, mostrándolo en oración y con la imagen de la Virgen sobre la representación de la batalla, sin rastro ya de los santos. Así aparece en el cuadro pintado en 1673 por Lazzaro Baldi para la iglesia del Colegio Ghisleri de Pavía que él había fundado; en la obra de Lucas Valdés, realizada para el convento dominico de San Pablo de Sevilla poco después de su canonización y hoy en la parroquia de Santa María Magdalena ${ }^{17}$; o en el lienzo anónimo del Museo Naval de Madrid, pintado a finales del siglo XVII para el convento de los dominicos de Málaga, en el que un ángel le gira la cabeza para que vea la victoria sobre la flota otomana mientras que desde el balcón que se abre en su oratorio se divisa una procesión del Rosario, con frailes dominicos, por las calles de la ciudad de Málaga ${ }^{18}$.

Pero fueron los principales protagonistas de la batalla los primeros que atribuyeron la victoria a la intercesión de la Virgen María, cada uno a la advocación por la que sentían más devoción. Entre los venecianos era ésta la Virgen de Loreto, a la que muchos se encomendaron para salir con vida de la batalla, haciendo voto de visitar la Santa Casa:

"De aquí fue que no sólo los cautivos que quedaron libres pero los más capitanes y soldados vinieron a N. Señora de Loreto en cumplimiento de sus votos, donde los cautivos ofrecieron sus cadenas en señal de su

${ }^{16}$ Miguel Bonelli (1541-1598), dominico, cardenal Alessandrino, hijo de una sobrina de Pío V que lo creó cardenal en 1566.

17 El templo parroquial es la antigua iglesia del convento de San Pablo, habiendo desaparecido el resto de los edificios conventuales tras la desamortización.

${ }^{18}$ MÍNGUEZ CORNELLES, V., “Auxilium Habsburgicum. La Virgen del Rosario y Lepanto", en MÍNGUEZ, V. y RODRÍGUEZ, I., La piedad de la Casa de Austria. Arte, dinastía y devoción, Gijón 2018, pp. 51-53. 
libertad, los capitanes y soldados despojos de los enemigos en señal de vencimiento y todos reconocieron este beneficio y dieron gracias a la Madre de Dios" $"$.

Don Juan de Austria, que también hizo voto de acudir a Loreto, lo cumplió aprovechando el año del jubileo Lauretano de 1576, entregando una joya de gran valor como exvoto, además de una crecida suma de dinero ${ }^{20}$. Pero no olvidó las dos advocaciones marianas más famosas entonces en España, Guadalupe y Montserrat, haciendo llegar a ambos santuarios sendos fanales de la galera de Alí Pachá, el almirante en jefe de la armada turca, en cumplimiento de sus votos. El de Guadalupe, entregado en 1573, lo describe así el P. Talavera en su Historia:

"Entre todas estas luces campea aquel vistoso fanal, en su grandeza y obra maravilloso, que se trujo de la galera capitana del gran Bajá cuando el serenísimo príncipe don Juan de Austria, hijo del emperador Carlos quinto, alcanzó aquella milagrosa victoria naval contra la poderosa armada de Selim segundo, monarca de los otomanos. Consagróla y dotóla a Nuestra Señora de Guadalupe la piedad y devoción de su hermano el rey Philipo, agradecido de su favor, año de mil y quinientos y setenta y uno"21.

Marco Antonio Colonna, que había enviado a su esposa a Loreto al partir él para reunirse con la flota en Mesina, a su regreso victorioso a Roma visitó la iglesia de Santa María in Aracoeli donde ofreció una columna de plata, el emblema de su linaje, con esta inscripción: "Marco Antonio, hijo de Ascanio, capitán de la armada del Pontífice, después de la insigne victoria contra los turcos, en reconocimiento de la merced ofreció este voto"22. Por su parte, don Álvaro de Bazán atribuyó a la Virgen de las Nieves, "la de junto a Almagro", el haber salido con bien de la batalla y en agradecimiento, antes de morir, encargó a su hijo, el segundo Marqués de Santa Cruz, la reedificación de la primitiva ermita ${ }^{23}$. Don Luis de Requesens, comendador mayor de Castilla de la orden de Santiago desde 1546, fundó tras la victoria naval un convento de franciscanos observantes en el lugar de Villarejo de Salvanés, sede de su encomienda, para lo que obtuvo licencia del Consejo de Órdenes en abril de 1572, en cuya iglesia conventual

19 TURSELINO, H., Historia Lauretana, en que se cuentan las translaciones, milagros y sucesos de la santa casa de N. Señora de Loreto. En Madrid, en casa de P. Madrigal, año 1603, f. $203 \mathrm{v}$.

${ }^{20}$ Ibidem, ff. 207-208.

${ }^{21}$ TALAVERA, G. de, Historia de Nuestra Señora de Guadalupe, en Toledo, en casa de Juan Guzmán, 1597, f. 156 v.

${ }^{22}$ FUENMAYOR, A., Vida y hechos de Pio V, f. 139.

${ }^{23}$ DÍEZ DE BALDEÓN, C., Almagro. Arquitectura y sociedad, Toledo 1993, pp. 261-263. 
entronizó una imagen de la Virgen con la advocación de Nuestra Señora de la Victoria, que la tradición quiere que le fuera entregada por Pío V siendo embajador del rey Felipe II ante la Santa Sede y que don Luis la llevara en su galera durante la batalla ${ }^{24}$.

Además, Requesens solicitó y obtuvo de Pío V indulgencias y gracias especiales para todos aquéllos que visitaran la capilla de su palacio en Barcelona, donde también se veneraba a la Virgen de la Victoria, el día 7 de octubre de cada año ${ }^{25}$, así como para los cofrades de la cofradía del Rosario de Martorell, villa perteneciente a su señorío, a los que concede la celebración de la fiesta, con jubileo plenísimo perpetuo, el día 7 de octubre en conmemoración de la batalla de Lepanto ${ }^{26}$. Hasta entonces, cada cofradía del Rosario celebraba la fiesta en diferentes días: en Venecia y México el 25 de marzo, en Sicilia el domingo in albis, en Cataluña el segundo domingo de mayo. Fue su sucesor, Gregorio XIII, el que estableció la celebración de la fiesta de Nuestra Señora del Rosario para todas sus cofradías e iglesias que tuvieran un altar a ella dedicado el primer domingo de octubre, en virtud de que el 7 de octubre de 1571 fue domingo ${ }^{27}$. Esta concesión se irá extendiendo poco a poco al conjunto de las iglesias de una región o de una diócesis, con motivo de la conmemoración el centenario de Lepanto en 1671, o con ocasión de nuevas victorias frente al turco, como el levantamiento del sitio de Viena en 1683. En 1716, después del triunfo del príncipe Eugenio de Saboya en la batalla de Peterwaradin (el 5 de agosto) y el fracaso del sultán Ahmet III ante Corfú (el 22 de agosto), Clemente XI hará de la solemnidad del Rosario una fiesta de la Iglesia universal introduciéndola en el calendario romano ${ }^{28}$.

${ }^{24}$ MIER, E. de, El santuario de la Virgen de la Victoria, Santander 1898; JIMÉNEZ HORTElANO, S., "Un proyecto inédito de Pedro de Tolosa: El convento de Santa María de la Victoria de Villarejo de Salvanés", en GÓMEZ-FERRER, M. y GIL SAURA, Y., Ecos culturales, artísticos y arquitectónicos entre Valencia y el Mediterráneo en Época Moderna, Valencia 2018, pp. 269-287.

${ }^{25}$ Bula Ineffabilia gloriosa Virginis de 15 de febrero de 1572.

${ }^{26}$ Breve Salvatoris Domini de 5 de marzo de 1572: Bullarium Ordinis FF Praedicatorum, Tomus quintus ab anno 1550 ad 1621, Romae, ex typographia Hieronymi Mainardi, 1733, pp. 295-297.

${ }^{27}$ Bula Monet Apostolus de 1 de abril de 1573: Bullarium Romanum novissimum a Pio IV usque ad Inocentium $I X$, tomus secundus, Romae, ex typographia Rev. Camerae Apostolicae, 1638, pp. 281-282.

${ }^{28}$ ROMERO MENSAQUE, C., "Los comienzos del fenómeno rosariano en la España moderna. La etapa fundacional, siglos XV y XVI", en Hispania Sacra (Madrid), 66 (2014) 243-278; y "La universalización de la devoción del Rosario y sus cofradías en España. De Trento a Lepanto", en Angelicum (Roma), 90 (2013) 217-246. LABARGA, F., "Historia del culto y devoción en torno al Santo Rosario", en Scripta Theologica (Pamplona), 35 (2003/1) 153-176. 


\section{LA FIESTA EN LA CATEDRAL DE TOLEDO}

\subsection{La dotación}

La fundación por Felipe II de una memoria en la catedral de Toledo para conmemorar cada 7 de octubre la milagrosa victoria naval no guarda ninguna relación con la fiesta de Nuestra Señora del Rosario, entonces limitada a sus cofradías, sino tan solo ofrecer al Altísimo una acción de gracias "por la victoria que el dicho año pasado de quinientos y setenta y uno Nuestro Señor fue servido de darnos contra la armada del Turco, enemigo de nuestra santa fe cathólica".

Para la dotación de dicha memoria llegó a un acuerdo con el Cabildo por el que permutaba la dehesa de Barciles ${ }^{29}$, propiedad de la catedral y tasada en 42.126.648' 5 mrs. por las que ellos eligieron y Felipe II entregó a la Obra y Fábrica catedralicia ${ }^{30}$ :

- Primero, las partes que en las dehesas de Castrejón, Albaladejo y el Allozar ${ }^{31}$ tenían el Colegio de doncellas de Nuestra Señora de los Remedios y el señor de la villa de Cedillo ${ }^{32}$, a quienes se las ha comprado el monarca, y que se tasaron en $24.733 .662 \mathrm{mrs}$.

- Segundo, la dehesa de Vergonzas ${ }^{33}$, que era del rey y fue tasada en 14.103.532 mrs.

- Tercero, la dehesa de Alcantarilla, que también era del Colegio de doncellas ${ }^{34}$, valorada en 7.289.454 mrs.

A cambio del exceso en el valor de lo entregado por la dehesa de Barciles (4.000.000 de maravedíes en la dehesa de Alcantarilla), el monarca quería que la

${ }^{29}$ Se encontraba en la ribera del Tajo, lindando con los sotos y términos del lugar de Añover y los sotos y dehesas de la encomienda Aceca, que son del monarca. Felipe II pretende incorporar la dehesa de Barciles al real sitio de Aranjuez.

${ }^{30}$ Permuta que hizo el rey don Phelippe $2^{\circ}$, nuestro señor, año de MDLXXIIII de las partes de la dehesa de Castrejón, Albadalejo y el Allozar y Alcantarilla y la dehesa de Vergonzas para la santa Iglesia de Toledo por la dehesa de Barciles con cargo que la obra pague la dotación de la batalla naval de Lepanto. San Lorenzo, 4 de septiembre de 1574. ACT, Secretaría Capitular, 70bis, ff. 33-45.

${ }^{31}$ Las tres dehesas están juntas, se encuentran a cinco leguas aguas abajo del Tajo, lindando con los términos de la Puebla de Montalbán, el lugar de Cubillete y la villa de Gálvez.

${ }^{32}$ Don Antonio Álvarez de Toledo y Luna, regidor de la ciudad de Toledo.

${ }^{33}$ Situada en la jurisdicción de Toledo, a dos leguas de la ciudad, en las riberas de los ríos Tajo y Guadarrama, y que linda con la dehesa de Estiviel, propiedad del mariscal de Novés, y con la dehesa de Cabrillos, del duque de Maqueda.

${ }^{34} \mathrm{Se}$ encontraba en la jurisdicción de Toledo, a tres leguas de la ciudad, lindando con la dehesa del Castañar y los términos de Sonseca y Mazarambroz. 
Obra "fuese obligada de dar al Cabildo de la dicha santa Iglesia lo que pareciese justo para dotación de la memoria" anual de Lepanto. Lo que se concertó entre ellos, Cabildo y Obra, fue la renta anual de $37.500 \mathrm{mrs}$ (100 ducados) sobre las dichas dehesas, con los que se habría de pagar la citada memoria de la batalla naval.

\subsection{La fiesta litúrgica}

El 27 de septiembre de 1574 se reunieron el deán y el cabildo junto con el gobernador general y administrador eclesiástico del arzobispado, don Sancho Busto de Villegas, y el canónigo obrero, don García de Loaysa, para aceptar la dotación de la memoria de Lepanto y establecer cómo habría de celebrarse la fiesta litúrgica; y el deán y cabildo se obligaron a lo siguiente ${ }^{35}$ :

"Primeramente, que en cada año a siete de octubre perpetuamente se celebre la dicha fiesta con la misma solemnidad y pompa que se celebran en la dicha sancta yglesia la del triumpho de la Sancta Cruz, que es la de las Navas de Tolosa, y la de Benamarín ${ }^{36}$, y la toma de Orán, y la conversión de los moros de Granada, y otras semejantes victorias; entendiéndose que ha de ser con la solemnidad que se celebra la que más solemnemente se haze destas fiestas.

Que el día de la tal fiesta no se ponga de guardar en la ciudad, sino que la solemnidad se haga solamente dentro de la dicha sancta yglesia.

Que el cabildo de la sancta yglesia tenga cuenta con que avisar en cada un año, un día antes, de las primeras vísperas al prelado que por tiempo fuere, $\mathrm{y}$ al corregidor y ayuntamiento, y a los inquisidores, para que se hallen presentes a la celebración de la dicha fiesta.

Que también se avise a los capellanes de las capillas de los Reyes Nuevos y Viejos, y de la reina doña Catalina, para que con sus sobrepellizes se hallen presentes a la dicha fiesta, asentándose en las sillas baxas del choro.

Que se avise y mande a todos los curas y beneficiados de las parrochias de la dicha ciudad de Toledo que para el día de la dicha fiesta se hallen presentes con las cruzes dellas a la procesión que se ha de hazer el día de la dicha fiesta antes de la misa, como se haze en las fiestas de las dichas victorias.

${ }^{35}$ Dotación e institución por el cabildo de la catedral de Toledo de la memoria de la victoria naval de Lepanto. Toledo, 27 de septiembre de 1574. Archivo General de Simancas, Patronato Real, 38-76.

${ }^{36}$ La batalla del Salado, 30 de octubre de 1340, contra los Benimerines. 
Que el officio de la dicha fiesta ha de ser de sanct Marcos papa y confesor, que es a siete de octubre y se celebra en tal día conforme al Breviario nuevo Romano y por cuyos méritos también es de creer que Nuestro Señor concedió la victoria.

Y para que la dicha fiesta se pueda hazer y celebrar con la solemnidad que las otras semejantes. El cabildo de la dicha sancta yglesia ha de impretar breve de Su Santidad para hazer doble en este sancta yglesia la fiesta del dicho papa sanct Marcos, pues sin esta facultad no se puede celebrar doble.

Que en la procesión que se ha de hazer el dicho día siete de octubre antes de la misa, después de la tercera estación se comience Te Deum laudamus cantando un verso los cantores y otro los menestriles y otro el órgano hasta llegados al choro, y acabado el hymno de Te Deum laudamus se digan las oraciones con sus versos competentes, la una de Nuestra Señora patrona de la dicha sancta yglesia, la otra Pro gratiarum actione, como está en el Misal nuevo, y donde dizen aquellas palabras Pro collatis donis, en lugar de ellas se digan las siguientes, Pro collata Regi nostro Philippo de clase turcarum navali victoria etc., y que ni se haga officio propio ni oraciones sino las dichas, como están en el Misal, añadiendo lo que aquí se dize y no más.

Que en la misa de la dicha fiesta se digan tres oraciones, la primera del sancto Marcos papa; la segunda de los sanctos mártyres que aquel día pasan por conmemoración; y la tercera Pro gratiarum actione, de la manera que se dixo en el fin de la procesión; y si la dicha fiesta cayere en domingo, las oraciones se ordenarán conforme a las reglas del Misal.

Que en la misa de la dicha fiesta aya cada un año sermón, el qual encomiende el cabildo a persona que le pareciere, y se le dé la limosna acostumbrada, advirtiéndole de lo que ha de dezir acerca de la fiesta conforme a la relación que dello ay en la yglesia.

Que en la dicha fiesta se saquen y cuelguen en la dicha sancta yglesia las vanderas e insignias desta victoria, que para ello se les darán, y las pongan de la manera que se ponen las vanderas en la fiesta del triumpho de la Cruz en la victoria de las Navas de Tolosa y la de Orán.

Que los cien ducados que se dan para la dotación de esta fiesta, que por orden de su Magestad la fábrica y la obra de la dicha sancta yglesia ha de dar en cada un año al cabildo de la dicha sancta yglesia se repartan en distribuciones, parte a los que estuvieren en las primeras vísperas, parte a los que estuvieren en la misa y procesión, y parte a los que estuvieren 
presentes en las segundas vísperas, señalando a cada una de las dichas horas y officios lo que al cabildo paresciere, con tanto que se distribuyan por entero los dichos cien ducados.

Que las dichas distribuciones no las puedan ganar sino solamente los presentes e interesentes [sic] a los dichos officios, y que no las ganen los ausentes, aunque estén ocupados en negocios de la sancta yglesia ni en otros, por legítimos que sean.

Que los enfermos que dos días antes de la fiesta estuvieren escusados por enfermedad ganen las dichas distribuciones, como si actualmente estuviesen presentes a todos los officios de la dicha fiesta.

Que aunque en la dicha sancta yglesia de Toledo las dignidades que no son canónigos no ganan distribuciones, la voluntad de su Magestad es que en esta fiesta todas las dignidades de la dicha sancta yglesia que estuvieren presentes a los officios de la dicha fiesta, o enfermos dos días antes, como dicho es, ganen y se les den las dichas distribuciones, aunque no sean canónigos, y de la manera y en la quantidad que se ha de dar y da a los canónigos de la dicha sancta yglesia, porque tengan cuenta de rogar a Dios por su Magestad.

Que todo lo que se ordenase sobre esta fiesta, y de la institución y dotación de esta memoria, se hagan dos libros del mismo tenor, el uno para enbiar al archivo de Simancas y el otro quede en el archivo de la sancta yglesia, por donde se rija el cabildo y sepa lo que se ha de hazer y a lo que está obligado, y la dicha fiesta se asiente en el calendario de las fiestas y memorias que en la dicha sancta yglesia se celebran".

Lo descrito tan pormenorizadamente es una fiesta litúrgica postridentina, en todo ajustada al ritual del nuevo Misal romano. Como el santo del día es el papa san Marcos, los oficios, las antífonas, las lecturas y las oraciones eran las que correspondían a un confesor pontífice. Ahora bien, para que la fiesta tuviera una mayor solemnidad el cabildo debía solicitar a Roma la concesión particular a la catedral de Toledo de fiesta doble, es decir con primeras y segundas vísperas, gracia que alcanzó de Pablo V el 28 de noviembre de 1610.

Desde el año 1611, la fiesta comenzaba la tarde del día 6, con el rezo de las primeras Vísperas a las que asisten el ayuntamiento de la ciudad -corregidor, regidores y jurados- bajo mazas, que ocupaba el lado de la epístola dentro del coro mayor; y los inquisidores y oficiales del Santo Oficio, situados en el lado del evangelio del mismo coro. También los capellanes de las tres capillas de Reyes de la catedral, que tomaban asiento en las sillas bajas del coro. Ese día se colgaban 
entre los dos coros diez banderas de la batalla. Ayuntamiento e Inquisición volverán a ser invitados a participar en la procesión y la misa del día siguiente.

El día 7 se rezaba Prima a las siete de la mañana, seguida de Tercia. Concluida ésta daba comienzo la procesión por las naves del templo con las cruces de las parroquias de la ciudad. Se hacen en ella tres estaciones, una de san Marcos -el santo del día-, en la capilla de San Ildefonso; la segunda de los santos, en el sagrario donde se guardan las reliquias; y la tercera de Nuestra Señora, ante la imagen de la Virgen de la Estrella en la puerta del Perdón. Se entona entonces el Te Deum laudamus y, cantando a tres coros, uno de ellos el órgano, la procesión prosigue hasta llegar al crucero donde se hace la cuarta estación. Acabada ésta entran en el coro las dignidades, canónigos y racioneros mientras el preste y los diáconos se dirigen al altar mayor para la celebración de la misa solemne, cantada. Tras la lectura del Evangelio hay sermón, del versículo: Vigilate quia nescitis qua hora Dominus vester venturus sit, del capítulo 24 de san Mateo, y en el que el predicador introducirá la narración de la batalla de Lepanto ${ }^{37}$. Concluida la misa rezan Sexta. Por la tarde, a la hora habitual, dicen Nona y a las dos y media las segundas Vísperas, de san Marcos, con solemnidad de procesión y órgano. Concluidas las Vísperas dicen Completas ${ }^{38}$. Los cien ducados que la Obra entrega para la fiesta se distribuyen entre los asistentes a cada una de las cuatro partes de la fiesta litúrgica: primeras Vísperas, procesión, Misa y segundas Vísperas, a razón de veinticinco ducados en cada una de ellas.

La fiesta siguió celebrándose, invariable, salvo por la presencia de la Inquisición, durante siglos. En 1885 Juan Moraleda y Esteban la describía en La Voz Provincial:

"Comienza con procesión por el ámbito de la catedral, a la que asisten las cruces parroquiales de la ciudad, seguidos del Cabildo y Municipio, y al final de la procesión se entona el Te Deum en acción de gracias por la celebrada victoria. Sigue luego la santa Misa, que se canta a atril por los dependientes de la Iglesia, hecha por el representante del Cabildo al Municipio, que torna en compañía terminando la ceremonia con la despedida de sus maceros y reyes de armas a las Casas Consistoriales. Es

${ }^{37}$ En las fiestas religiosas barrocas ocupaba un lugar muy destacado la predicación de sermones, piezas de oratoria sagrada compuestas para la ocasión. La conmemoración de Lepanto se asocia a la Virgen del Rosario, advocación vinculada a los dominicos y será en sus iglesias de distintas ciudades donde tengan lugar estos sermones que, en muchos casos, luego fueron entregados a la imprenta, como el predicado en la catedral de Toledo en 1618 (fig. 3).

${ }^{38}$ El racionero Juan Chaves Arcayos describe los distintos elementos de la fiesta en su Ceremonial. ACT, Ms. 42-29, ff. 379-380. 
de advertir que no todos los años asiste el Municipio. Ante tan majestuosa solemnidad, iqué de ideas se acumulan en nuestra imaginación!"39.

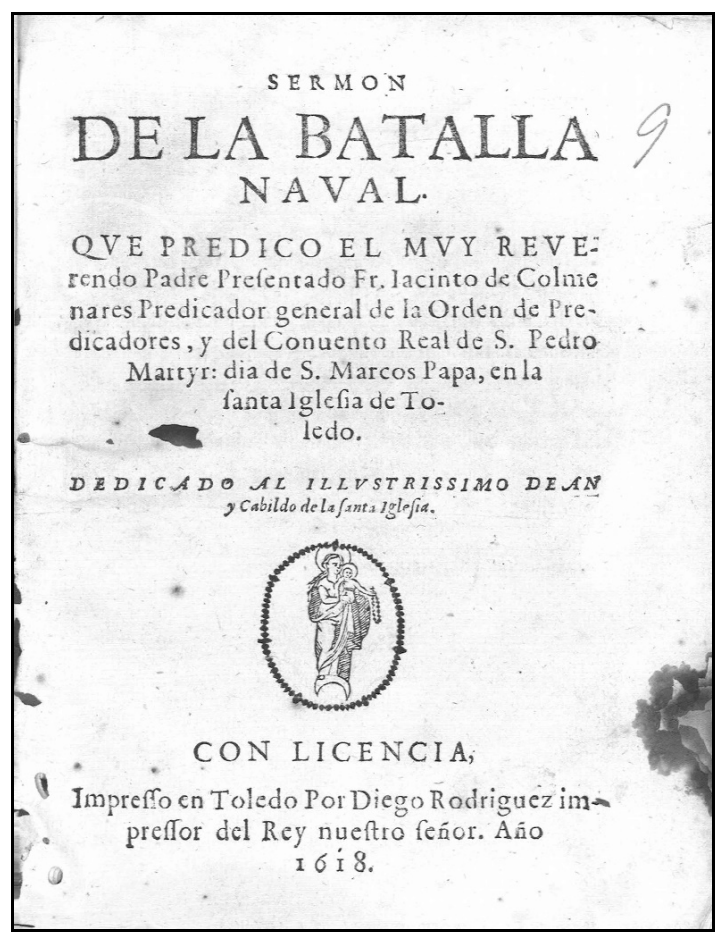

Figura 3: Sermón de la Batalla Naval, predicado en la catedral de Toledo el 7 de octubre de 1618 .

¿Hasta cuándo se celebró? No soy capaz de decirlo, la última de la que he logrado constancia documental fue la del año 1935, según publicaba el diario toledano El Castellano en el número del día 7 de octubre:

"Hoy se ha celebrado solemne función religiosa en la Catedral con motivo de celebrarse el aniversario de la victoria de las armas españolas en la batalla de Lepanto. Hubo procesión por las naves del templo, celebrándose después misa solemne, en la que ofició el canónigo muy ilustre señor don José María Basés, asistido de los beneficiados señores Blanco y Aguilera. La capilla catedralicia interpretó la misa del maestro Perossi. Asistieron numerosos fieles".

${ }^{39}$ El artículo fue luego recogido en MORALEDA Y ESTEBAN, J., Fiestas toledanas. Folletín de la Campana Gorda, Toledo 1893, pp. 30-31. 
Todo parece indicar que tras la guerra civil no se recuperó la celebración de esta memoria anual. La prensa local se hizo eco de que el sábado día 7 de octubre de 1939 los turistas que visitaban la catedral se sorprendieron al ver colgada una de las banderas de Lepanto, pero no dice nada de la celebración de la fiesta ${ }^{40}$.

\section{LAS BANDERAS DE LEPANTO}

En el acuerdo entre Felipe II y el cabildo de Toledo para la realización de la memoria por la batalla naval de Lepanto se establecía que el día de la fiesta se expondrían "unas banderas y otras insignias" de la victoria que el monarca había de remitir a la catedral. Se seguía en ello el mismo ritual que en otras celebraciones: el triunfo de la Cruz, que conmemoraba la victoria en la batalla de las Navas de Tolosa, y la toma de Orán por el cardenal Cisneros, que fue quien instituyó la fiesta. En ambas ocasiones se exhibían banderas y estandartes conservados en el tesoro de la catedral. Según el Inventario de las reliquias y alhajas del Sagrario, hecho en 1619 , las banderas y pendones de las Navas eran once ${ }^{41}$, y siete los de Orán ${ }^{42}$.

${ }^{40}$ Diario El Alcázar del 10 de octubre de 1939 p. 2, columna Crónica local, con el título de "La bandera de Lepanto".

41 "Pendones de la Victoria de las Nabas de Tolosa:

1) Un pendón de seda amarilla que tiene una parte una cruz grande colorada y de la parte una cabeça de Nuestra Señora, y por estar muy viejo se adereçó con tafetán blanco. Y esta cabeça de Nuestra Señora en la misma parte que la cruz.

2) Otro pendón amarillo con una figura de Nuestra Señora con su Hijo en braços y un Arçobispo de rodillas. Y está tan gastado todo, que casi no se debisa.

3) Otro pendón de listas coloradas y blancas, en las blancas ay unos armiños y en medio las armas de la Iglesia. Está tam biejo que casi no se echa de ber.

4) Otro pendón largo colorado con una figura de Sanctiago a caballo y quatro beneras. Está tan viejo que no se echa de ber.

5) Otro pendón de seda blanca con armas del Papa Martino Quinto. Está tan biejo que no se echan de ber las armas.

6) Otro pendón de seda blanca con una cruz colorada que le atrabiesa todo.

7) Otro pendón morisco amarillo cercado de letras arábigas con diez y seis lunas con letras negras.

8) Otro pendón grande con los çercos de labores moriscas y en medio diez y seis lunas de oro y dentro dellas letras arábigas.

9) Un pendón de tafetán negro que sirbe la Dominica in Pasione. Tiene una cruz de Calatraba de oro con una lista e raso colorado en medio y tiene flueco de oro a la redonda.

10) Otro pendón de tafetán blanco que tiene en medio la figura de Sant Eugenio.

11) Otro pendón de tafetán blanco con la figura de Santa Leocadia en medio. Tiene flueco de seda carmesí y dos borlas en las puntas de oro y seda carmesí”.

Inventario de las reliquias y alhajas del Sagrario de la Catedral realizado en sede vacante por orden del Cabildo en el momento en que Alonso de Ortega, racionero, dejó su oficio de 
Las banderas de Lepanto tardaron en llegar a Toledo, aunque don Juan de Austria remitió a Felipe II parte de los despojos de los vencidos que le cupieron en el reparto tras la victoria: fanales de galera, armas y banderas y estandartes. Cuando el monarca ordenó la creación de la Real Armería, junto al Real Alcázar de Madrid, ordenó que estas piezas fueran trasladadas allí. Según consta por los inventarios de la Armería las banderas y estandartes de Lepanto que ingresaron fueron 11 piezas con grandes cordones y borlas de seda azul y oro (que son de la armada de la Liga Santa) y 34 banderas turcas.

En 1616 las banderas prometidas todavía no habían sido remitidas a la catedral por lo que el cabildo las reclamó. El lunes 1 de agosto se trató el asunto capitularmente y acordaron escribir al obispo de Tortosa ${ }^{43}$ con un traslado de la cláusula de la escritura de dotación de la fiesta en la que se hace relación a las banderas y otras insignias de la batalla de Lepanto "para que el dicho señor obispo dé memorial a su Magestad y trate con el señor Patriarca de las Indias que se cumpla la dicha cláusula"44. Las gestiones dieron su fruto y Felipe III ordenó que se enviasen a la catedral cinco de las banderas de la Liga Santa y dieciséis banderas otomanas de las que se conservaban en la Real Armería ${ }^{45}$. En la fiesta de

sacristán mayor del Sagrario en favor de Pedro Martínez de Torres, [Toledo], 1619. ACT, Secretaría Capitular, Inventarios 34, ff. 142-143.

42 "Pendones de la Victoria de Orán:

- Un pendón pequeño de seda blanca con una cruz en medio verde, negra, blanca y dorada, de la forma de la cruz de la Charidad con un letrero alrededor de letras antiguas que diçe: Hec est enim victoria quae uincit mundum, maestrito [sic].

- Seis pendones que se ponen en las rejas de los choros en la fiesta de la Victoria. Están hechos pedaços, los dos son moros y los otros quatro el uno es del Papa Sisto, el otro de los Reyes Cathólicos, el otro es de fray Francisco Ximénez, arçobispo desta Santa Yglesia, el otro tiene una cruz verde".

Inventario de las reliquias y alhajas del Sagrario. ACT, Secretaría Capitular, Inventarios 34, f. 142.

${ }^{43}$ Luis de Tena, canónigo de Toledo y preconizado obispo de Tortosa.

${ }^{44}$ ACT, Libro de Actas Capitulares, v. 27, f. 159.

45 "Pendones de la Batalla Nabal con que se celebró en Roma la Victoria della, y Su Santidad los embió a la Magestad del rey don Phelipe $2^{\circ}$ y el rey don Phelipe $3^{\circ}$ su hijo los dio a esta Santa Iglesia para que se pongan entre los dos [coros] el día que se çelebra la fiesta desta Victoria:

1) Un pendón muy largo de damasco azul y labores doradas por todo el cuerpo y remata en dos puntas. Tiene en la parte de arriba un Christo pequeño y debajo dél quatro escudos de armas de la Liga, abraçadas con tiene de largo treinta y dos baras, poco más o menos.

2) Otro pendón más pequeño del mismo del mismo damasco y labores doradas por todo el cuerpo, con un Christo en la parte de arriba y debajo otros quatro escudos de armas de la Liga asidor con su cadena. Tiene de largo 19 baras poco más o menos.

3) Otro pendón más pequeño que los dos precedentes de la misma tela y labor con un Christo al trabés y debajo dél las armas de la Liga asídas con su cadena. Tiene de largo cinco baras poco más o menos. 
aquel año se colgaron, por primera vez en el coro, las banderas de los turcos y los estandartes de Lepanto, según acuerdo capitular ${ }^{46}$ :

"Jueves 6 de octubre 1616. Naval: Los dichos señores, capitularmente ayuntados, mandaron que las diez y seis banderas con los estandartes de la batalla nabal que su Magestad mandó dar y a embiado el señor doctor Tena, obispo de Tortosa, se pongan esta tarde que se hace la fiesta por la victoria".

No sabemos cuál era la disposición de las banderas más que se colocaban "entre los dos coros". Tiempo después se colocaron en el triforio del crucero, sobre las naves de la Epístola y del Evangelio, a ambos lados de la reja del altar mayor, y allí fueron fotografiadas en dos ocasiones, una por Casiano Alguacil, hacia 1885, y la otra por Abelardo Linares, hacia 1915. Las fotografias de Alguacil nos permiten ver que en el lado del Evangelio se colocaban la flámula grande de la galera de don Juan de Austria y, a ambos lados, el gallardete y el tordano (figura 4), y en el lado de la Epístola el estandarte o pendón y el pico de gallo o pinelo (figura 5). Años después, cuando las fotografió Linares, la flámula aparece sola (figura 6).

Las fotografías de Casiano Alguacil fueron reproducidas en el artículo que a "Las banderas de Lepanto" dedicó en el número de octubre de 1921 de Toledo. Revista de Arte el director del Museo de la Infantería del Alcázar de Toledo, don Hilario González ${ }^{47}$. No era la primera vez que lo hacía, aunque nunca con ilustraciones: en octubre de 1914 publicó una serie de artículos en El Castellano y al año siguiente otros dos en Toledo, también en el mes de octubre. En todos ellos concluía con una llamada al cabildo "para que ponga el mayor esmero, $\mathrm{y}$ con toda urgencia, en contener el inminente estado de ruina a que se hallan expuestas estas enseñas de Lepanto".

4) Un estandarte grande del mismo damasco y labores, con un Christo al trabés grande, con los quatro escudos de la Liga. Tiene ocho anchos de la seda por lo más ancho y ba rematando en punta. Tiene de largo nuebe baras poco más o menos.

5) Otro pendón muy grande del mismo damasco y labores. Tiene un Christo muy grande y los quatro escudos de la Liga a los pies. Remata en dos puntas. Tiene la parte de arriba diez anchos de la seda. Tiene de largo veinte y dos baras poco más o menos.

6) Diez gallardetes turquescos de dibersas sedas muy viejos y hechos pedaços.

7) Otros seis gallardetes turquescos de lienço de dibersos colores, muy rotos".

Inventario de las reliquias y alhajas del Sagrario. ACT, Secretaría Capitular, Inventarios 34, ff. 143-144.

${ }^{46}$ ACT, Libro de Actas Capitulares, v. 27, f. 178.

47 GONZÁlEZ, H., "Las banderas de Lepanto en la Catedral de Toledo", en Toledo. Revista de Arte (Toledo), 176 (1921) 185-190. 


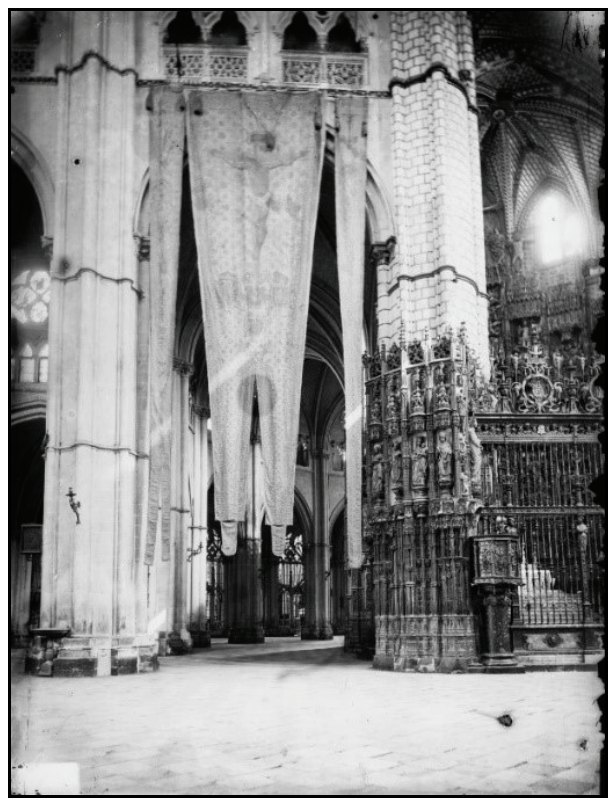

Figura 4: Casiano Alguacil: Vista del crucero, lado del Evangelio, con las banderas de Lepanto, Archivo Municipal de Toledo (AMT), CA-175.

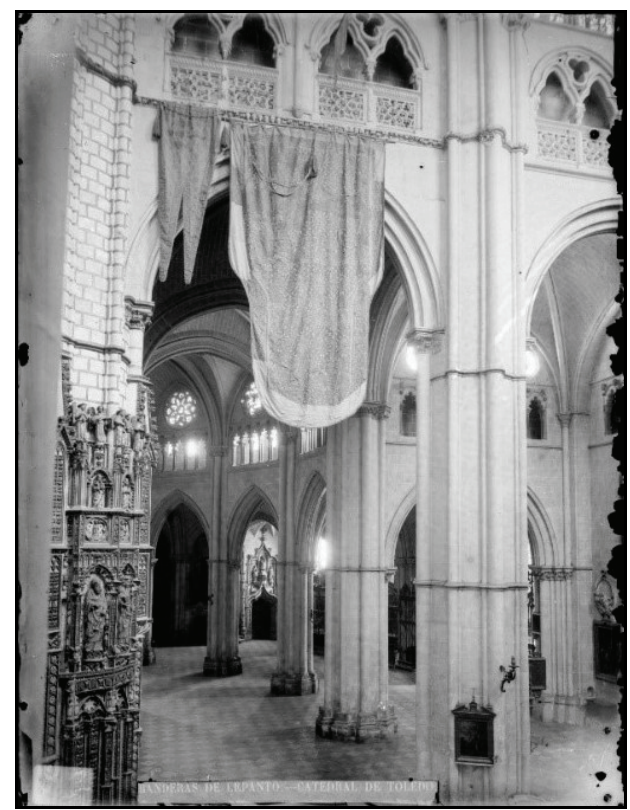

Figura 5: Casiano Alguacil: Vista del crucero, lado de la Epistola, con las banderas de Lepanto, AMT, CA-174. 


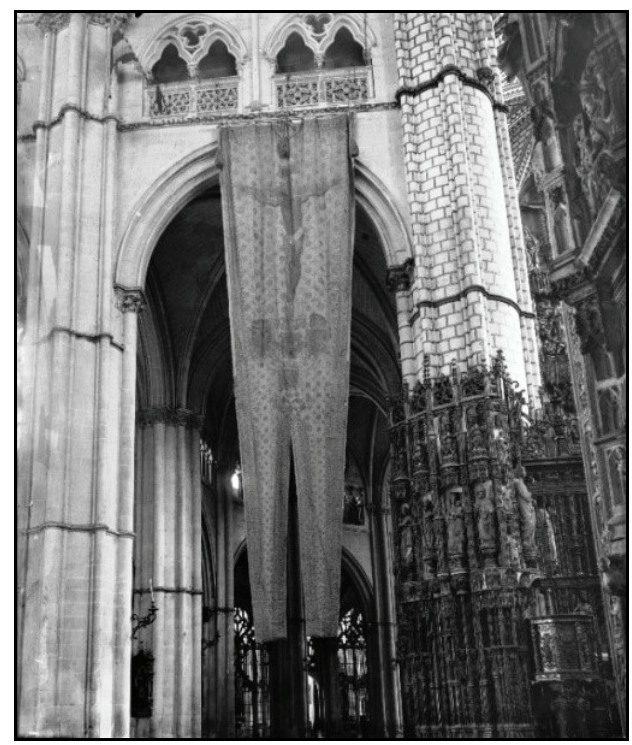

Figura 6: Abelardo Linares: Banderas de la batalla de Lepanto, AMT, PAREJA-VI-554.

El deterioro de las banderas había comenzado mucho antes y afectó más a las otomanas. En el inventario de los objetos de la catedral realizado por orden del cardenal Lorenzana en 1790 sólo aparecen nueve banderas otomanas y los cinco pendones de la Liga. Sin embargo, en los posteriores a 1815 ya no hay ninguna mención a las banderas turcas. Cuando Cesáreo Fernández Duro, el gran historiador de la Armada, las estudió no quedaban en la catedral más que las cinco enseñas de la Liga Santa ${ }^{48}$, siendo él el primero en señalar la diferencia heráldica entre ellas: la flámula grande, el estandarte y el pinelo llevan el escudo de Pío V, son de 1571 y estuvieron en la galera Real en la batalla de Lepanto ${ }^{49}$; el gallardete y el tordano llevan las armas de Gregorio XIII y deben fecharse entre el 25 de mayo de 1572 (fecha del inicio de su pontificado) y el 7 de marzo de 1573 (disolución de la Liga Santa por parte de Venecia) no pudiendo, por tanto, haber estado en Lepanto ${ }^{50}$.

${ }^{48}$ FERNÁNDEZ DURO, C., "Estandarte de la Liga y espada que San Pío V envió al Serenísimo Don Juan de Austria", en Boletín de la Real Academia de la Historia (Madrid), 13 (1888) 299-306, y "Pormenores del estandarte de la Liga Santa", en Boletín de la Real Academia de la Historia (Madrid), 14 (1889) 427-432.

${ }^{49}$ En 1961 la catedral las cedió en depósito al Museo de Santa Cruz, donde estuvieron expuestas hasta que su colección permanente fue desinstalada en el año 2000 destinándose, desde entonces, a exposiciones temporales. Hoy sólo puede verse el pinelo, mientras que el estandarte y la flámula grande permanecen en los depósitos.

${ }^{50}$ Las dos piezas se conservan en la catedral pero, por sus grandes dimensiones, no están expuestas. 


\section{BIBLIOGRAFÍA}

- ALFARO, Fray G. de, Vida del Illustríssimo Señor Don Francisco de Reynosso, obispo de Córdoba. En Valladolid, por Francisco Fernández de Córdoba, 1617.

- ANTONIO, N., Bibliotheca Hispana Nova, Romae, ex Officina Nicolai Angeli Tinasii, 1672, vol. I.

- BULLARIUM Ordinis FF Praedicatorum, Tomus quintus ab anno 1550 ad 1621. Romae, ex typographia Hieronymi Mainardi, 1733.

- BULLARIUM Romanum novissimum a Pio IV usque ad Inocentium IX, tomus secundus, Romae, ex typographia Rev. Camerae Apostolicae, 1638.

- DÍEZ DE BALDEÓN, C., Almagro. Arquitectura y sociedad, Toledo 1993.

- ENTRAMBASAGUAS, J. de, Vida ejemplar de Francisco de Reinoso, Abad de Husillos y Obispo de Córdoba, Valladolid 1940.

- FERNÁNDEZ DURO, C., "Estandarte de la Liga y espada que San Pío V envió al Serenísimo Don Juan de Austria", en Boletín de la Real Academia de la Historia (Madrid), 13 (1888) 299-306,

- FERNÁNDEZ DURO, C., "Pormenores del estandarte de la Liga Santa", en Boletín de la Real Academia de la Historia (Madrid), 14 (1889) 427-432.

- FUENMAYOR, A. de, Vida y hechos de Pío V, Pontifice Romano, con algunos notables sucesos de la Christiandad del tiempo de su Pontificado. En Madrid, por Luis Suárez, 1595.

- GONZÁLEZ, H., "Las banderas de Lepanto en la Catedral de Toledo", en Toledo. Revista de Arte (Toledo), 176 (1921) 185-190.

- JIMÉNEZ HORTELANO, S., "Un proyecto inédito de Pedro de Tolosa: El convento de Santa María de la Victoria de Villarejo de Salvanés", en GÓMEZ-FERRER, M. y GIL SAURA, Y., Ecos culturales, artísticos y arquitectónicos entre Valencia y el Mediterráneo en Época Moderna, Valencia 2018, pp. 269-287.

- LABARGA, F., "Historia del culto y devoción en torno al Santo Rosario", en Scripta Theologica (Pamplona), 35 (2003/1) 153-176.

- MIER, E. de, El santuario de la Virgen de la Victoria, Santander 1898. 
- MÍNGUEZ CORNELLES, V., "Auxilium Habsburgicum. La Virgen del Rosario y Lepanto", en MÍNGUEZ, V. y RODRÍGUEZ, I., La piedad de la Casa de Austria. Arte, dinastía y devoción, Gijón 2018.

- MÍNGUEZ CORNELLES, V., "Iconografía de Lepanto. Arte, propaganda y representación simbólica de una Monarquía universal y católica", en Obradoiro de Historia Moderna (Santiago de Compostela), 20 (2011) 255-284.

MÍNGUEZ CORNELLES, V., Infierno y gloria en el mar. Los Habsburgo y la imagen artística de Lepanto (1430-1700), Castellón de la Plana 2018.

- MORALEDA Y ESTEBAN, J., Fiestas toledanas. Folletín de la Campana Gorda, Toledo 1893.

- RIVERO RODRÍGUEZ, M., La batalla de Lepanto. Cruzada, guerra santa e identidad confesional, Madrid 2008.

- ROMERO MENSAQUE, C., "La universalización de la devoción del Rosario y sus cofradías en España. De Trento a Lepanto", en Angelicum (Roma), 90 (2013) 217-246.

- ROMERO MENSAQUE, C., "Los comienzos del fenómeno rosariano en la España moderna. La etapa fundacional, siglos XV y XVI", en Hispania Sacra (Madrid), 66 (2014) 243-278.

- SAN MARTÍN PAYO, J., "Notas históricas sobre la Abadía de Husillos", en Publicaciones de la Institución Tello Téllez de Meneses (Palencia), 64 (1993) 197-236.

- TAlAVERA, Fray G. de, Historia de Nuestra Señora de Guadalupe. En Toledo, en casa de Juan Guzmán, 1597.

- TURSELINO, H., Historia Lauretana, en que se cuentan las translaciones, milagros y sucesos de la santa casa de N. Señora de Loreto. En Madrid, en casa de P. Madrigal, año 1603. 
